\title{
Distinct regulation of tonic GABAergic inhibition by NMDA receptor subtypes
}

\author{
Kunwei $\mathrm{Wu}^{1}$, David Castellano ${ }^{1}$, Qingjun $\operatorname{Tian}^{1}$ and Wei Lu ${ }^{1,2, *}$ \\ ${ }^{1}$ Synapse and Neural Circuit Research Section, National Institute of Neurological \\ Disorders and Stroke, National Institutes of Health, Bethesda, MD 20892, USA \\ ${ }^{2}$ Lead Contact
}

*Correspondence: luw4@mail.nih.gov

\section{SUMMARY}

Tonic inhibition mediated by extrasynaptic $\gamma$-aminobutyric acid type A receptors $\left(G_{A B A} R s\right)$ play important roles in the regulation of various brain functions. However, the regulatory mechanisms for tonic inhibition remain largely unknown. Here we report distinct actions of GluN2A- and GluN2B-containing subtypes of NMDA receptors (NMDARs) on tonic inhibition in hippocampal neurons. Mechanistically, GluN2A- and GluN2B-containing NMDARs play differential roles in $\alpha 5-G A B A_{A} R$ internalization. Additionally, GluN2A-, but not GluN2B-, containing receptors are required for the homeostatic potentiation of tonic inhibition. In an acute seizure model induced by kainic acid, tonic inhibition is decreased during acute seizures, while it is increased $24 \mathrm{~h}$ later, and these alterations are dependent on the distinct GluN2-containing NMDARs. Collectively, these data reveal a critical link between NMDARs and extrasynaptic $\mathrm{GABA}_{\mathrm{A}} \mathrm{Rs}$ in both physiological and pathological conditions. 


\section{INTRODUCTION}

$\gamma$-aminobutyric acid (GABA), the major inhibitory neurotransmitter in the adult mammalian brain, exerts its fast inhibitory effects by acting on ubiquitously expressed $\gamma$ aminobutyric acid type $A$ receptors $\left(G_{A B A} R s\right)$. $G A B A_{A} R s$ can be classified as mediating phasic or tonic inhibition (Belelli et al., 2009; Farrant and Nusser, 2005). Phasic inhibition is mediated by $\mathrm{GABA}_{\mathrm{A}}$ Rs localized at synapses and activated by GABA released presynaptically in the synaptic cleft, whereas tonic inhibition is mediated by $\mathrm{GABA}_{\mathrm{A}} \mathrm{Rs}$ localized outside the synapses (extrasynaptic and perisynaptic) and activated by the low ambient levels of GABA in the extracellular space. Accumulating evidence has revealed that tonic inhibition is involved in a variety of brain functions, including regulating neuronal excitability, neural circuit function, synaptic plasticity, and neuronal development (Belelli et al., 2009; Brickley and Mody, 2012; Farrant and Nusser, 2005; Holter et al., 2010; Lee and Maguire, 2014). Although the molecular and cellular mechanisms regulating phasic inhibition have been extensively studied (Han et al., 2021; Jacob et al., 2008; Luscher et al., 2011; Vithlani et al., 2011), regulatory mechanisms for tonic inhibition remain less clear.

NMDA receptors (NMDARs) are heteromeric complexes assembled from the GluN1 and GluN2 or GluN3 subunit (Chatterton et al., 2002; McBain and Mayer, 1994). The GluN2 subunit has four isoforms (GluN2A to GluN2D), which are differently distributed across the central nervous system (Monyer et al., 1992). In the adult brain, both GluN2A and GluN2B are the predominant GluN2 subunits in the hippocampus (Monyer et al., 1994). GluN2A- and GluN2B-containing NMDARs display differences in their pharmacological and biophysical properties including kinetics, sensitivity to various ligands, permeability to divalent ions, and interactions with intracellular proteins (Vieira et al., 2020). They also have distinct roles in regulating neuronal development (Gambrill and Barria, 2011; 
Gonda et al., 2020; Sepulveda et al., 2010) and are implicated in pathological conditions such as epilepsy (Chen et al., 2007) and stroke (Chen et al., 2008).

Recent studies have also revealed that NMDARs play an important role in the regulation of GABAergic synapse development and function (Chiu et al., 2018; Gaiarsa, 2004; Gu and Lu, 2018; Gu et al., 2016; Henneberger et al., 2005; Horn and Nicoll, 2018; Marsden et al., 2007; Petrini et al., 2014; Rajgor et al., 2020). However, much less is known about the role of NMDARs in the regulation of tonic GABAergic inhibition. It has been shown that genetic deletion of GluN1, the obligatory subunit of the NMDAR, leads to an enhancement of tonic inhibition in immature hippocampal neurons (Gu et al., 2016). In addition, pathological activation of NMDARs during stroke decreases expression of extrasynaptic $\delta$-subunit-containing $\mathrm{GABA}_{\mathrm{A}} \mathrm{Rs}$ and reduces tonic currents in cortical neurons (Jaenisch et al., 2016). However, a systematic investigation of NMDAR regulation of tonic inhibition is lacking. It is also unknown whether the subunit composition of NMDARs is critical for tonic inhibition regulation. Here we employed genetic and pharmacological approaches to demonstrate the differential roles of GluN2A- and GluN2B-containing subtypes of NMDARs in the regulation of extrasynaptic $\mathrm{GABA}_{\mathrm{A}} \mathrm{R}$ trafficking and tonic inhibition. 


\section{RESULTS}

\section{Overexpression of GluN2B inhibits tonic inhibition}

To assess the role of GluN2 subunits in modulation of tonic inhibition, we first overexpressed GluN2A or GluN2B in cultured hippocampal neurons at DIV11, and then measured miniature inhibitory postsynaptic currents (mIPSCs) and tonic inhibitory currents at DIV14 (Figure 1A). We observed that tonic currents were significantly reduced in neurons overexpressing GluN2B, whereas overexpression of GluN2A had no effect on tonic currents, compared to control neurons overexpressing GFP (Figure 1B and $1 \mathrm{C})$. However, neither GluN2A nor GluN2B overexpression had a significant effect on mIPSCs (Figure S1), indicating a subunit specific function of GluN2 in regulating tonic, but not phasic, inhibition. Previous work has shown that extrasynaptic $\alpha 5-G A B A_{A} R s$ mediate the majority of tonic inhibition in hippocampal pyramidal neurons (Caraiscos et al., 2004; Glykys et al., 2008). To investigate whether overexpression of GluN2 subunits regulated the abundance of surface $\alpha 5-G A B A_{A} R s$, we performed $\alpha 5-G A B A_{A} R$ immunostaining assays in cultured hippocampal neurons. Consistent with the effect on tonic currents (Figure 1B), overexpression of GluN2B, but not GluN2A or the control, GFP, reduced the surface expression of $\alpha 5-G A B A_{A}$ Rs (Figure 1C).

\section{Knockout of GluN2A and GluN2B differentially regulate tonic inhibition}

To complement the overexpression experiments, we developed single-guide RNAs (sgRNAs) to perform single-cell genetic deletion of endogenous GluN2A or GluN2B in cultured hippocampal neurons and then measured tonic inhibitory currents (Figure 1D). The knockout (KO) efficacy was confirmed by Western blot in co-transfected HEK293 cells (Figure S2A and S2B) as well as by NMDA mEPSC and NMDA-evoked whole-cell current recordings in cultured neurons transfected with both sgRNAs (Figures S2C, S2D 
and S2E). We found that whereas sgRNA-mediated KO of GluN2A significantly decreased tonic currents, GluN2B KO increased tonic currents, compared with control neurons expressing empty vector (Figure 1E). Importantly, the changes in tonic currents induced by either GluN2A or GluN2B KO were restored back to the control level by coexpression of corresponding GluN2 sgRNA-resistant constructs (Figure 1E), suggesting that these effects were due to loss of GluN2A or GluN2B, but not off-target effects.

\section{Pharmacological suppression of GluN2A- and GluN2B-containing receptors modulate $\alpha 5-G A B A_{A} R$ surface expression and tonic inhibition}

To corroborate our genetic findings, we next employed pharmacological treatment to examine the role of GluN2A and GluN2B in the regulation of tonic inhibition. Specifically, we treated cultured hippocampal neurons at DIV15 with NVP-AAM077 (NVP, GluN2Apreferring antagonist; $100 \mathrm{nM}$ ), ifenprodil (Ifen, GluN2B-preferring antagonist; $5 \mu \mathrm{M}$ ) or APV (broad-spectrum NMDAR antagonist; $100 \mu \mathrm{M}$ ) for $24 \mathrm{~h}$, and then measured tonic inhibitory currents. We found that Ifen increased surface $\alpha 5$ expression and tonic inhibitory currents, whereas NVP induced opposite effects (Figures 2B and 2C). In addition, APV had little effect on surface $\alpha 5$ expression and tonic currents (Figures 2B and $2 \mathrm{C}$ ), indicating that blockade of both of GluN2A- and GluN2B-containing NMDARs exerts a combinatory effect leading to little change in tonic inhibition. Taken together, these results suggest the differential regulation of $\alpha 5$ surface expression and tonic inhibition by GluN2A- and GluN2B-containing receptors.

During development, NMDARs undergo a developmental switch from those containing primarily the GluN2B subunit to primarily the GluN2A subunit in neocortex and hippocampus (Dong et al., 2006; McKay et al., 2018; Sheng et al., 1994). Consistent with these previous studies, we confirmed the developmental switch from primarily 
GluN2B-containing receptors to primarily GluN2A-containing receptors in cultured hippocampal neurons (Figure S3A). In addition, both $G A B A_{A} R \alpha 5$ subunit expression and tonic currents were increased during development within the first month (Figures S3A and S3B), suggesting a possible link between developmental switch of NMDARs subunits and developmental increase of $\alpha 5-G A B A_{A} R$ expression within the first month. Thus, we tested the effects of GluN2A and GluN2B antagonists on tonic inhibition in immature and more differentiated neurons. In immature neurons at DIV7-8, Ifen or APV increased surface $\alpha 5$ expression and tonic currents, whereas NVP had little effect (Figures S3C and S3D), consistent with higher expression of GluN2B in developing, immature neurons. By contrast, in more differentiated neurons at DIV25-26, NVP and APV decreased surface $\alpha 5$ expression and tonic currents, whereas Ifen had little effect (Figures S3C and S3D). These results suggest that regulation of tonic inhibition by GluN2A and GluN2B is developmentally dependent.

\section{Pharmacological suppression of GluN2A- and GluN2B-containing receptors regulate $\alpha 5-G A B A_{A} R$ internalization}

Considering that opposite actions of GluN2A- and GluN2B-containing receptor blockade in $\alpha 5-G A B A_{A} R$ surface expression and tonic currents were observed at 2-3 weeks neurons, we thus investigated the mechanism underlying the distinct effects at this developmental stage in the following experiments. The abundance of surface $\alpha 5$ $\mathrm{GABA}_{A} \mathrm{Rs}$ is controlled by the balance of receptor endocytosis and exocytosis. Since surface expression of $\alpha 5-G A B A_{A} R$ s is differentially regulated by NMDAR GluN2 subunits, we hypothesized that $\alpha 5$ endocytosis and/or exocytosis might be critically regulated by GluN2A- or GluN2B-containing NMDARs. To test this hypothesis, we first performed antibody-feeding experiments to label surface and internalized endogenous $\alpha 5$ in live 
hippocampal neurons at DIV15 and examined $\alpha 5$ endocytosis. We found that 24-h NVP treatment increased $\alpha 5$ internalization, whereas $24-\mathrm{h}$ Ifen treatment decreased $\alpha 5$ internalization (Figure 2D). In addition, 24-h APV treatment did not alter $\alpha 5$ internalization (Figure 2D). These results suggest that GluN2A and GluN2B have distinct role in regulating $\alpha 5-G A B A_{A} R$ internalization at this developmental stage. Next, we combined fluorescence recovery after photobleaching (FRAP) with fluorescence loss in photobleaching (FLIP) to investigate exocytosis of superecliptic pHluorin-tagged $\alpha 5$ (SEP- $\alpha 5)$ to measure the receptor exocytosis. In this experiment, repetitive photobleaching occurred at dendritic regions bilateral to the central FRAP area, thus excluding laterally diffusing SEP- $\alpha 5$ to the central area and allowing the measurement of newly exocytosed SEP- $\alpha 5$ (Figure S3E). We found that neurons under different treatments exhibited similar fluorescence recovery after photobleaching (Figure S3F), indicating that neither GluN2A- nor GluN2B-containing receptors regulate $\alpha 5$ exocytosis.

\section{GluN2A-containing receptors are required for homeostatic potentiation of tonic inhibition}

Chronic pharmacological manipulation of neuronal activity can induce homeostatic adaptions of excitatory and inhibitory transmission, which are powerful mechanisms controlling neuronal excitability and neural network function (Turrigiano, 2012). Our recent work has demonstrated that tonic inhibition in hippocampal neurons exhibited homeostatic plasticity (Wu et al., 2021). Consistent with this study, we found that surface $\alpha 5$ expression and tonic inhibition were increased following 48-h bicuculline treatment (Figure 3). To examine the role of GluN2A- and GluN2B-containing NMDARs in homeostatic plasticity of tonic inhibition, we treated hippocampal neurons at DIV16 with bicuculine $(40 \mu \mathrm{M})$ and $24 \mathrm{~h}$ later NVP $(100 \mathrm{nM})$, Ifen $(5 \mu \mathrm{M})$ or APV $(100 \mu \mathrm{M})$ was 
administered for $24 \mathrm{~h}$ before recording. We found that bicuculline-induced effects were significantly diminished by treatment of NVP and APV, but not by Ifen (Figure 3). These observations support a necessary role for GluN2A-, but not GluN2B-, containing NMDARs in homeostatic potentiation of tonic inhibition.

\section{Pharmacological suppression of GluN2A- and GluN2B-containing receptors regulate tonic inhibition in the KA-induced seizure model}

Finally, we examined whether GluN2-dependent regulation of $\alpha 5-G A B A_{A} R s$ may occur under pathological conditions. To this end, we induced the acute seizure model by systematic administration of kainic acid (KA), an agonist for kainate- and AMPA-type ionotropic glutamate receptors. All mice injected with $\mathrm{KA}(20 \mathrm{mg} / \mathrm{kg})$ showed epileptic behavior within 30 min and completely recovered $24 \mathrm{~h}$ after injection (Figure S4A). We then analyzed the total and surface expression levels of GluN2A, GluN2B and GABA $A_{A}$ s in hippocampal slices prepared from mice at $1 \mathrm{~h}$ or $24 \mathrm{~h}$ after KA injection (Figure S4B). We found that KA administration had little effect on the total expression level of NMDAR and $\mathrm{GABA}_{A} R$ subunits, comparing with saline-injected control (Figures $4 A, B$ and $C$ ). In contrast, 1-h post-KA injection produced a significant increase of surface GluN2B, but not GluN2A (Figure 4A and 4B). Interestingly, at $24 \mathrm{~h}$ after KA injection, surface GluN2A was increased, whereas surface GluN2B was unaffected (Figure 4A and 4B). As expected from the regulation of surface $\alpha 5$ expression by GluN2A- and GluN2Bcontaining receptors (Figure $2 C$ ), surface expression of $\alpha 5-G A B A_{A} R$ was decreased at 1 $\mathrm{h}$, and then increased at $24 \mathrm{~h}$ after $\mathrm{KA}$ injection (Figure $4 \mathrm{C}$ ). In addition, surface $\alpha 1$ $\mathrm{GABA}_{A} \mathrm{R}$ was increased at $24 \mathrm{~h}$ after $\mathrm{KA}$ injection (Figure $\mathrm{S} 4 \mathrm{C}$ ). These results suggest the expression of GluN2 subunits and synaptic and extrasynaptic $\mathrm{GABA}_{A}$ Rs are dynamically regulated by the KA-induced seizure. 
It has been shown that the CA3 region of the hippocampus plays a critical role in KAinduced seizures (Vincent and Mulle, 2009). We thus recorded the tonic currents in CA3 pyramidal cells (Figures S4D). In keeping with the alterations of surface $\alpha 5$ expression after KA injection, we found that whereas tonic currents in hippocampal CA3 neurons were decreased significantly in KA-administrated mice $1 \mathrm{~h}$ after induction, they were increased $24 \mathrm{~h}$ after induction compared to control mice administrated with saline (Figures 4D and 4E). Interestingly, Ifen (10 mg/kg) or NVP (10 mg/kg) treatment $1 \mathrm{~h}$ prior to $\mathrm{KA}$ injection respectively restored the decreased or increased tonic currents at corresponding time point after KA injection (Figures 4D and 4E). These results suggest that KA-induced changes of tonic inhibition are dependent on distinct GluN2-containing NMDARs in a temporal-specific manner. In contrast, the mIPSC amplitude was increased $24 \mathrm{~h}$ after KA treatment compared with saline treatment, but blockade of GluN2A- or GluN2B-containing NMDARs had little effect on this alteration (Figures S4E and S4F), indicating KA-induced increase of phasic inhibition is independent on GluN2Aand GluN2B-containing NMDARs. 


\section{DISCUSSION}

In this study, we investigate the role of GluN2A- and GluN2B-containing NMDARs towards the regulation of tonic inhibition. Our genetic and pharmacological analyses indicate opposing actions of GluN2A- and GluN2B-containing NMDARs on $\alpha 5-G A B A_{A} R$ internalization and tonic inhibition in hippocampal neurons. In addition, GluN2A- but not GluN2B-containing receptors are required for homeostatic potentiation of tonic inhibition. In a KA-induced acute seizure model, while tonic inhibition is decreased during acute seizures, it is increased $24 \mathrm{~h}$ later and these alterations are dependent on the activity of the distinct GluN2-containing NMDARs. Collectively, these data extend previous work showing the importance of NMDARs in regulating inhibitory synapse development and transmission (Chiu et al., 2018; Gu and Lu, 2018; Gu et al., 2016; Horn and Nicoll, 2018) and reveal an important crosstalk between glutamatergic signaling and extrasynaptic $\mathrm{GABA}_{\mathrm{A}} \mathrm{Rs}$.

\section{Differential regulation of tonic inhibition by NMDA receptor subtypes}

It has been reported that extrasynaptic $\mathrm{GABA}_{\mathrm{A}} \mathrm{R}$-mediated tonic inhibition is regulated by neurotransmitter receptor-mediated signaling. Indeed, activation of $\mathrm{GABA}_{B}$ receptors enhances tonic inhibition in thalamocortical, dentate gyrus, and cerebellar granule cells (Connelly et al., 2013). Additionally, glycine receptors could interact with $\alpha 5-G A B A_{A} R s$ and regulate tonic currents in the neurons of hypoglossal nucleus (Zou et al., 2019). In addition to inhibitory receptors, tonic inhibition is modulated by glutamatergic receptors expressed at excitatory synapses. For example, genetic deletion of GluN1 leads to augmentation of tonic inhibition in immature hippocampal neurons (Gu et al., 2016). In line with this study, here we found that pharmacological blockade of GluN2B-containing NMDARs, the predominant NMDAR subtype expressed in immature neuron or blockade 
of all NMDARs enhanced tonic inhibition in immature neurons. Interestingly, we also found that the effect of blockade of GluN2B-containing NMDARs on tonic inhibition disappeared in the more differentiated neurons. The temporal-specific regulation is likely caused by the differential expression of NMDAR GluN2 subunits during development. Indeed, in the hippocampus, during the first 2 weeks after birth, NMDARs undergo a developmental switch from predominantly GluN2B- to GluN2A-containing receptors (Dong et al., 2006). This may also explain the lack of effects on tonic inhibition by blockade of GluN2A-containing receptors in immature neurons. For the 2-3 weeks neurons when both GluN2A and GluN2B are abundantly expressed, opposite actions of GluN2A- and GluN2B-containing receptor blockade on tonic inhibition were observed. Interestingly, inhibition of all NMDARs by APV abolished the differential modulation of tonic inhibition by NMDAR subtypes, presumably due to the normalization of opposing effects of GluN2A- and GluN2B-containing receptors on extrasynaptic GABA $A_{A}$ s. Of note, although both pharmacological inhibition and genetic deletion of GluN2A diminished tonic inhibition in the 2-3 weeks neurons, overexpression of GluN2A had no significant effect on tonic inhibition, showing that further increase in GluN2A expression over endogenous levels at this developmental stage is not sufficient to alter tonic inhibitory currents.

Currently, the molecular mechanisms underlying the regulation of tonic inhibition by NMDARs remain unclear. One scenario is that GluN2A- and GluN2B-containing receptors are coupled to distinct downstream phosphatase and kinase pathways (Shipton and Paulsen, 2014; Sun et al., 2018; Wu and Tymianski, 2018), which in turn may differentially regulate $\alpha 5-G A B A_{A} R$ trafficking and tonic inhibition. For instance, it has been reported that activation of GluN2A- and GluN2B-containing receptors differentially regulates ERK1/2 (Chen et al., 2007) and Akt activities (Liu et al., 2007). In addition, 
blocking GluN2A-containing receptors attenuates ischemic preconditioning-induced the transcription factor CREB phosphorylation in CA1 pyramidal neurons, whereas blocking GluN2B-containing receptors has little effect (Chen et al., 2008; Terasaki et al., 2010), showing that NMDAR subtypes can activate different signaling pathways. However, it remains unknown whether these molecular pathways are involved in the regulation of $\alpha 5-G A B A_{A} R$ trafficking and tonic inhibition. It has been shown that $\alpha 5-G A B A_{A} R$ trafficking could be regulated in a phosphorylation-dependent manner. Indeed, phosphorylation of radixin, a cytoskeletal protein binding to $\alpha 5-\mathrm{GABA}_{\mathrm{A}} \mathrm{Rs}$, increases $\alpha 5$ $\mathrm{GABA}_{\mathrm{A}} \mathrm{R}$ clustering at the extrasynaptic sites (Hausrat et al., 2015; Loebrich et al., 2006). In addition, phosphorylation of Shisa7, a GABA ${ }_{A} R$ auxiliary subunit (Han et al., 2019), can regulate $\alpha 5-G A B A_{A} R$ trafficking and tonic inhibition (Wu et al., 2021), although Shisa7 primarily modulates $\alpha 5-G A B A_{A} R$ exocytosis. These findings raise the possibility that GluN2A- and GluN2B-containing receptors might differentially regulate tonic inhibition through modulation of phosphorylation of molecules that are involved in $\alpha 5$ $\mathrm{GABA}_{A} \mathrm{R}$ trafficking. It is worth noting that CaMKII activation leads to an increase in cellsurface $\alpha 5 \beta 3$-containing receptors and an enhancement of tonic currents (Saliba et al., 2012), and conversely blockade of CaMKII activity causes a reduction of tonic currents in hippocampal neurons (Wu et al., 2021). Interestingly, GluN2A- and GluN2B-containing receptors can differentially regulate CaMKII activity (Strack, McNeill, and Colbran 2000; Barria and Malinow 2005), which in turn might contribute to distinct modulation of $\alpha 5$ $\mathrm{GABA}_{A} \mathrm{R}$ trafficking and tonic inhibition. It has also been reported that activation of GluN2A- and GluN2B-containing NMDARs results in differential expression of brain derived neurotrophic factor (BDNF) triggered by distinct intracellular signaling (Chen et al., 2007). BDNF has been implicated in the regulation of cell-surface expression of extrasynaptic $\mathrm{GABA}_{\mathrm{A}} \mathrm{Rs}$ containing $\alpha 4$ and $\delta$ subunits in hippocampal neurons (Joshi 
and Kapur, 2009; Roberts et al., 2006). However, it remains to be determined whether extrasynaptic $\alpha 5-G A B A_{A}$ Rs are similarly modulated by BDNF in an NMDAR subtypespecific manner. In the future, it will be important to determine how GluN2A- and GluN2B-containing NMDARs can distinctly modulate tonic inhibition.

\section{Alterations in tonic inhibition in epilepsy}

It has been reported that GluN2B-containing NMDARs play an important role in the pathophysiology of epilepsy (Waxman and Lynch, 2005; Zhang and Luo, 2013). Specifically, the calcium influx through extrasynaptic GluN2B-containing NMDARs blocks BDNF expression by inactivating CREB and leads to mitochondrial dysfunction and cell death (Hardingham and Bading, 2010; Hardingham et al., 2002). Upregulation of GluN2B mRNA was also found in pyramidal cells of non-sclerotic hippocampi from epileptic patients (Mathern et al., 1998). In an animal model of epilepsy induced by pilocarpin, a cholinergic muscarinic agonist, surface accumulation of GluN2B-containing NMDARs in the hippocampus has been reported (Muller et al., 2013; Naylor et al., 2013). In addition, it has been shown that a decrease in $\alpha 5$-containing GABA $_{A}$ Rs occurs in CA1 pyramidal cells of pilocarpine-treated rats (Houser and Esclapez, 2003). In this study, we show that KA injection induces upregulation of surface GluN2B and downregulation of surface $\alpha 5-G A B A_{A} R$ in the hippocampus $1 \mathrm{~h}$ after $K A$ injection. Together with the experiments demonstrating that GluN2B-containing NMDARs regulate $\alpha 5-G A B A_{A} R$ internalization, our data indicate that an increase of GluN2B-containing receptors contributes to the reduction of surface $\alpha 5-G A B A_{A} R$ by enhancing endocytosis, resulting in downregulation of tonic inhibition during acute seizures. Given that the important role

of tonic inhibition in regulating neural network excitability (Belelli et al., 2009; Farrant and Nusser, 2005; Lee and Maguire, 2014), GluN2B receptor-mediated reduction of tonic 
inhibition may contribute to KA-induced neuronal hyperexcitability and epileptogenesis in the seizure model.

Our data also show that in the KA-induced acute seizure model, whereas epileptic phenotypes disappear $24 \mathrm{~h}$ after KA induction, tonic inhibition in hippocampal CA3 neurons is increased. Consistently, a recent study using a similar seizure model has shown that enhanced neuronal excitability in cortical neurons returns to the basal level and tonic inhibition is increased $24 \mathrm{~h}$ after KA injection (Pan et al., 2018). Additionally, in the pilocarpine-induced seizure model, the tonic current is enhanced in dentate gyrus granule cells 3 weeks after induction (Naylor et al., 2005). Thus, an increase of tonic inhibition after acute seizure appears to be a common phenotype across different neuronal types in different seizure models. What is the functional significance of the increased tonic current $24 \mathrm{~h}$ later after acute seizures? Considering the importance of tonic GABAergic signaling in regulating neural network excitability (Belelli et al., 2009; Farrant and Nusser, 2005; Lee and Maguire, 2014), the increase in tonic inhibition that occurs after acute seizures may act as a homeostatic adaptive response to KA-induced neuronal hyperexcitability, and thus may help lessen neurodegeneration associated with neuronal hyperexcitability. We also found that homeostatic potentiation is dependent on the GluN2A subunit. In the adult forebrain, GluN2A-containing receptors are predominantly localized at synaptic sites and activation of synaptic NMDARs is considered to be neuroprotective (Hardingham and Bading, 2010; Hardingham et al., 2002). Therefore, GluN2A-dependent upregulation of tonic inhibition after KA-induced seizure may provide additional evidence supporting the neuroprotective effects of GluN2A-containing receptors in neurodegenerative disorders (Liu et al., 2007; Terasaki et al., 2010). In addition, in line with a previous report (Peng et al., 2010), we found that the phasic inhibition could undergo the homeostatic potentiation after KA administration. 
However, homeostatic potentiation of synaptic inhibition is independent of GluN2A, suggesting distinct mechanisms governing homeostatic plasticity of tonic and phasic inhibition induced by KA.

Taken together, we have uncovered a critical role of NMDARs in the regulation of $\alpha 5-$ $\mathrm{GABA}_{\mathrm{A}} \mathrm{R}$ trafficking and tonic inhibition during development and in a seizure model, and revealed distinct roles of NMDAR subtypes in regulating tonic inhibition in a development-specific manner. As dysregulations of tonic inhibition has been shown to be a mechanism underlying a variety of pathological brain states (Brickley and Mody, 2012; Hines et al., 2012), our findings also offer insight into developing more selective treatment of a diverse array of neurological and psychiatric disorders. 


\section{Acknowledgements}

We are grateful to all members from Wei Lu laboratory for critical comments on the manuscript. This work was supported by the NIH/NINDS Intramural Research Program (W.L.).

\section{Author Contributions}

K.W. and W.L. designed the project, and W.L. supervised the project. K.W. performed imaging, biochemical and behavioral experiments, and electrophysiological recordings. K.W. and D.C. cloned sgRNA constructs. Q.T. performed neuronal cultures. W.L. and K.W. wrote the manuscript, and all authors read and commented on the manuscript.

\section{Declaration of Interests}

The authors declare no competing interests. 


\section{STAR METHODS}

\section{Resource Availability}

\section{Lead contact}

Further information and requests for resources and reagents should be directed to the Lead Contact, Wei Lu (luw4@mail.nih.gov).

\section{Materials Availability}

All unique reagents generated in this study are available from the Lead Contact with a completed Materials Transfer Agreement.

\section{Data and Code Availability}

This study did not generate datasets/code. 


\section{EXPERIMENTAL MODEL AND SUBJECT DETAILS}

\section{Animals}

All animal handling was performed in accordance with animal protocols approved by the Institutional Animal Care and Use Committee (IACUC) at NIH/NINDS. All mice were housed and bred in a conventional vivarium with ad libitum access to food and water under a 12-h circadian cycle. Time-pregnant mice at E17.5-18.5 were used for dissociated hippocampal neuronal culture. Young adult male mice (6-8 weeks old) were used for biochemical, electrophysiological, and behavioral experiments.

\section{Cell Lines}

HEK293T cells (ATCC, Cat\# CRL-11268) were maintained with culture media containing 1\% penicillin-streptomycin (GIBCO), 10\% FBS (GIBCO) in Dulbecco's Modified Eagle's Medium (DMEM, GIBCO), in a humidified incubator at $37^{\circ} \mathrm{C}$ with $5 \% \mathrm{CO}_{2}$.

\section{Dissociated Hippocampal Neuronal Culture}

Mice hippocampal neurons were prepared from E17.5-18.5 mice embryos of either sex as previously described (Wu et al., 2021). In brief, the hippocampi were dissected from embryonic brains and digested in the Hank's Balanced Salt Solution (HBSS, GIBCO) containing $20 \mathrm{U} / \mathrm{ml}$ papain (Worthington) and $100 \mathrm{U} / \mathrm{ml}$ DNase I (Worthington) at $37^{\circ} \mathrm{C}$ for $45 \mathrm{~min}$. After centrifugation for $5 \mathrm{~min}$ at $800 \mathrm{rpm}$, the pellet was resuspended in HBSS containing $100 \mathrm{U} / \mathrm{ml}$ DNase I, and was fully dissociated by pipetting up and down. Cells were then transferred into HBSS containing trypsin inhibitor $(10 \mathrm{mg} / \mathrm{ml}$, SigmaAldrich) and BSA (10 mg/ml, Sigma-Aldrich). After centrifugation for $10 \mathrm{~min}$ at $800 \mathrm{rpm}$, cells were resuspended in Neurobasal media (GIBCO) supplemented with 2\% B27 (GIBCO) and $2 \mathrm{mM}$ GlutaMAX (GIBCO) and were plated on poly-D-lysine (Sigma- 
Aldrich)-coated glass coverslips or 6-well plates. Cultures were maintained in Neurobasal media supplemented with 2\% B27 and 2 mM GlutaMAX in a humidified incubator at $37{ }^{\circ} \mathrm{C}$ with $5 \% \mathrm{CO}_{2}$. Culture media were changed by half volume once a week.

\section{METHOD DETAILS}

\section{Plasmids}

pRK5-GFP-GluN2A and pRK5-GFP-GluN2B were gifts from Katherine Roche's lab at NINDS, NIH. pSpCas9(BB)-2A-Puro (PX459) V2.0 and pSpCas9(BB)-2A-GFP (PX458) were purchased from Addgene. Custom oligonucleotides were generated (GluN2A forward, 5' CACCGCGACGTGACAGAACGCGAAC 3'; and GluN2A reverse, 5' AAACGTTCGCGTTCTGTCACGTCGC 3'; and GluN2B forward, 5' CACCGTCTGACCGGAAGATCCAGG 3'; and GluN2B reverse, AAACCCTGGATCTTCCGGTCAGAC 3'; IDT), and cloned into pSpCas9-BB-2A-GFP (PX458) or pSpCas9(BB)-2A-Puro (PX459) V2.0 vector at the Bbsl cutting site. The coding sequence of GluN2A and GluN2B point mutations for sgRNA resistant plasmid (GluN2A: ATGTCTGACCGGAAGATCCAGGGG to ATGTCTGAICGTAAGATICAㅁGGㅁ) were generated by Q5 Site-Directed Mutagenesis Kit (NEB).

\section{Cell Transfection}

HEK-293T cells were transfected with GluN2A or GluN2B, together with sgRNA using CalPhos Mammalian Transfection Kit (Takara). Western blot was performed $48 \mathrm{~h}$ after transfection. Hippocampal neurons at DIV3-4 were transfected with GluN2A sgRNA or GluN2B sgRNA using NeuroMag reagent (Oz Biosciences), and were recorded at 
DIV16-17. Hippocampal neurons at DIV11 were co-transfected with pCAG-IRES-GFP and GluN2A or GluN2B using NeuroMag reagent. Electrophysiological recordings or immunostaining were performed $72 \mathrm{~h}$ after transfection. All transfection kits were used according to the manufacturer's instructions.

\section{Electrophysiology}

For recording in dissociated hippocampal cultures, neurons were continuously perfused with the extracellular solution containing (in $\mathrm{mM}$ ): $140 \mathrm{NaCl}, 5 \mathrm{KCl}, 2 \mathrm{CaCl}_{2}, 1 \mathrm{MgCl}_{2}, 10$ HEPES, and 10 Glucose ( $\mathrm{pH} 7.3$; osmolality 300-310 mOsm). The internal solution contained (in mM): 70 CsMeSO4, $70 \mathrm{CsCl}, 8 \mathrm{NaCl}, 10$ HEPES, $0.3 \mathrm{Na}-\mathrm{GTP}, 4 \mathrm{Mg}$-ATP and 0.3 EGTA ( $\mathrm{pH} \mathrm{7.3;} \mathrm{osmolality} \mathrm{285-290} \mathrm{mOsm).} \mathrm{Miniature} \mathrm{inhibitory} \mathrm{postsynaptic}$ currents (mIPSCs) and tonic currents were recorded at $-70 \mathrm{mV}$ in the presence of 0.5 $\mu \mathrm{M}$ TTX (Alomone Labs) and $20 \mu \mathrm{M}$ DNQX (Alomone labs). For recording NMDA mEPSCs at $+40 \mathrm{mV}, 0.5 \mu \mathrm{M}$ TTX, $20 \mu \mathrm{M}$ DNQX, and $50 \mu \mathrm{M}$ picrotoxin (Sigma-Aldrich) were added into the extracellular solution. For recording NMDA-induced whole-cell currents, TTX $(0.5 \mu \mathrm{M})$ were added into $0 \mathrm{Mg}^{2+}$ extracellular solution. NMDA-induced current was recorded at $-70 \mathrm{mV}$ by rapid application/removal of NMDA (100 $\mu \mathrm{M})$ using a computer-controlled multi-barrel perfusion system (Automate Scientific).

For recording in acute brain slices, transverse hippocampal slices (300 $\mu \mathrm{m}$ thickness) were prepared from 6-8 weeks old male mice in chilled high sucrose cutting solution, containing (in mM): $2.5 \mathrm{KCl}, 0.5 \mathrm{CaCl}_{2}, 7 \mathrm{MgCl}_{2}, 1.25 \mathrm{NaH}_{2} \mathrm{PO}_{4}, 25 \mathrm{NaHCO}_{3}, 7$ glucose, 210 sucrose and 1.3 ascorbic acid. The slices were recovered in artificial cerebrospinal fluid (ACSF) containing (in mM): $130 \mathrm{NaCl}, 3.5 \mathrm{KCl}, 24 \mathrm{NaHCO}_{3}, 1.25 \mathrm{NaH}_{2} \mathrm{PO}_{4}-\mathrm{H}_{2} \mathrm{O}, 10$ glucose, $2.5 \mathrm{CaCl}_{2}$ and $1.5 \mathrm{MgCl}_{2}(\mathrm{pH} 7.3$; osmolality $300-310 \mathrm{mOsm})$ at $33^{\circ} \mathrm{C}$ for 30 min and then were maintained at room temperature prior to recording. To record tonic 
currents, slices were transferred to a submersion chamber, continuously perfused with ACSF with $0.5 \mu \mathrm{M}$ TTX, $20 \mu \mathrm{M}$ DNQX and $5 \mu \mathrm{M}$ GABA. The intracellular solution contained (in mM) $130 \mathrm{CsCl}, 8.5 \mathrm{NaCl}, 5$ HEPES, $4 \mathrm{MgCl}_{2}, 4 \mathrm{Na}-\mathrm{ATP}, 0.3 \mathrm{Na}-\mathrm{GTP}$ and 1 QX-314 (pH 7.3; osmolality 285-290 mOsm).

To measure tonic inhibitory currents in neuronal cultures or in acute hippocampal slices, the $\mathrm{GABA}_{A} \mathrm{R}$ competitive antagonist bicuculline $(20 \mu \mathrm{M}, \mathrm{Abcam})$ was bath applied after obtaining a stable baseline recording at $-70 \mathrm{mV}$. An all-points histogram was plotted for a 20-s period before and during bath-application of bicuculline, fitting the histogram with a Gaussian distribution gave the mean baseline holding currents, and the difference in baseline holding currents before and during bicuculline application was calculated to be the tonic currents. Tonic currents were normalized to membrane capacitance, to account for variability in cell size. Series resistance was monitored and not compensated, and cells in which series resistance was more than $25 \mathrm{M} \Omega$ or varied by $25 \%$ during a recording session were discarded. Whole-cell recordings were obtained from cells visualized with a fixed stage upright microscope (BX51WI, Olympus). Fluorescencepositive cells were identified by epifluorescence microscopy. Data were collected with a Multiclamp 700B amplifier (Axon Instruments), filtered at $2 \mathrm{kHz}$, and digitized at $10 \mathrm{kHz}$.

\section{Immunostaining}

For surface $\alpha 5$ receptor labeling, cultured hippocampal neurons at DIV15 on coverslips were incubated with anti- $\alpha 5$ antibody (1:500, Synaptic Systems) in culture medium for 15 min. Next, they were washed briefly with fresh culture medium and fixed with a solution containing 4\% paraformaldehyde and 4\% sucrose in PBS. Cultured neurons were subsequently incubated with Alexa 555-conjugated anti-rabbit secondary antibody (1:1000, Thermo Fisher Scientific) for the visualization of $\alpha 5$. For the endocytosis assay, 
cultured hippocampal neurons at DIV15 were incubated live with rabbit $\alpha 5$ antibody (1:500, Synaptic Systems) at $37^{\circ} \mathrm{C}$ for $10 \mathrm{~min}$ in conditioned culture medium. After incubation, the neurons were washed with PBS and then incubated in antibody-free medium to allow antibody-bound receptors to undergo internalization at $37^{\circ} \mathrm{C}$ for $30 \mathrm{~min}$, followed by fixation with $4 \%$ paraformaldehyde and $4 \%$ sucrose in PBS. After fixation, neurons were washed and then blocked with $10 \%$ NGS for $1 \mathrm{~h}$, exposed to Alexa 488conjugated anti-rabbit secondary antibody (1:200, Jackson ImmunoResearch Labs) for 1 $\mathrm{h}$ under the nonpermeabilized condition, and then internalized $\alpha 5$ was labelled with Alexa 555-conjugated anti-rabbit secondary antibody (1:1000, Thermo Fisher Scientific) for $1 \mathrm{~h}$ after permeabilization in PBS containing $0.25 \%$ Triton $\mathrm{X}-100$ and blocking in $10 \%$ NGS. Coverslips were washed for three times with PBS and mounted with FluoromountG.

Fluorescence images were acquired on a Zeiss LSM 880 laser scanning confocal microscope with a $63 \times 1.4$ NA oil immersion objective. For quantification, sets of cells were prepared and stained simultaneously. Compared images were acquired at the same time using identical acquisition settings. The fluorescence intensity was analyzed using ImageJ.

\section{Surface cell biotinylation of hippocampal slices}

Hippocampal slices were prepared from 6-8 weeks mice as described (Li et al., 2017). Surface expression of GluN2A, GluN2B, $\alpha 1-\mathrm{GABA}_{\mathrm{A}} R$ and $\alpha 5-\mathrm{GABA}_{\mathrm{A}} \mathrm{R}$ was quantitated as described. Briefly, acute hippocampal slices were labeled for 30 min at $4{ }^{\circ} \mathrm{C}$ with 1 $\mathrm{mg} / \mathrm{ml}$ sulfo-NHS-SS biotin (ThermoFisher Scientific). Membranes were prepared and the biotinylated proteins were precipitated with streptavidin agarose resin (ThermoFisher Scientific) and detected by western blot. 


\section{Kainic acid-induced seizure model}

Young adult male mice (6-8 weeks old) were administered an intraperitoneal (i.p.) injection of kainic acid (KA, Abcam) dissolved in $0.9 \%$ saline solution at $20 \mathrm{mg} / \mathrm{kg}$ body weight. Seizure score was evaluated at $0 \mathrm{~h}, 0.5 \mathrm{~h}, 1 \mathrm{~h}$ and $24 \mathrm{~h}$ after KA injection according to the modified Racine scale (Racine, 1972): stage 0, normal behavior; stage 1 , immobility and rigidity; stage 2, repetitive behaviors, head nodding or bobbing; stage 3 , Forelimb clonus with partial or intermittent rearing; stage 4, continuous rearing and falling; stage 5, severe clonic-tonic seizures; stage 6 , death. The expression levels of GluN2A, GluN2B and $\mathrm{GABA}_{\mathrm{A}} \mathrm{Rs}$ in hippocampi were examined at $1 \mathrm{~h}$ or $24 \mathrm{~h}$ after $\mathrm{KA}$ injection. To examine the effects of GluN2A- and GluN2B-containing receptors on the tonic inhibition in KA-induced seizure model, mice were injected with NVP (10 mg/kg), Ifen $(10 \mathrm{mg} / \mathrm{kg})$ or saline $1 \mathrm{~h}$ prior to $\mathrm{KA}$ injection and were sacrificed for electrophysiological recordings at $1 \mathrm{~h}$ or $24 \mathrm{~h}$ after KA injection.

\section{QUANTIFICATION AND STATISTICAL ANALYSIS}

\section{Statistical Analysis}

Statistical analysis was performed in GraphPad Prism 8.0 software. Normality distribution was tested by the Shapiro-Wilk test before carrying out a subsequent statistical test. Direct comparisons between two groups were made using two-tailed Student's $t$ test or Mann-Whitney $U$ test. Multiple comparisons were performed using one-way ANOVA, Kruskal-Wallis test or two-way ANOVA with corrections for multiple comparisons test (see figure legends for specifics). 


\section{References}

Belelli, D., Harrison, N.L., Maguire, J., Macdonald, R.L., Walker, M.C., and Cope, D.W. (2009). Extrasynaptic GABAA receptors: form, pharmacology, and function. The Journal of neuroscience : the official journal of the Society for Neuroscience 29, 12757-12763.

Brickley, S.G., and Mody, I. (2012). Extrasynaptic GABA(A) receptors: their function in the CNS and implications for disease. Neuron 73, 23-34.

Caraiscos, V.B., Elliott, E.M., You-Ten, K.E., Cheng, V.Y., Belelli, D., Newell, J.G., Jackson, M.F., Lambert, J.J., Rosahl, T.W., Wafford, K.A., et al. (2004). Tonic inhibition in mouse hippocampal CA1 pyramidal neurons is mediated by alpha5 subunit-containing gamma-aminobutyric acid type A receptors. Proceedings of the National Academy of Sciences of the United States of America 101, 3662-3667.

Chatterton, J.E., Awobuluyi, M., Premkumar, L.S., Takahashi, H., Talantova, M., Shin, Y., Cui, J., Tu, S., Sevarino, K.A., Nakanishi, N., et al. (2002). Excitatory glycine receptors containing the NR3 family of NMDA receptor subunits. Nature 415, 793-798.

Chen, M., Lu, T.J., Chen, X.J., Zhou, Y., Chen, Q., Feng, X.Y., Xu, L., Duan, W.H., and Xiong, Z.Q. (2008). Differential roles of NMDA receptor subtypes in ischemic neuronal cell death and ischemic tolerance. Stroke 39, 3042-3048.

Chen, Q., He, S., Hu, X.L., Yu, J., Zhou, Y., Zheng, J., Zhang, S., Zhang, C., Duan, W.H., and Xiong, Z.Q. (2007). Differential roles of NR2A- and NR2B-containing NMDA receptors in activity-dependent brain-derived neurotrophic factor gene regulation and limbic epileptogenesis. The Journal of neuroscience : the official journal of the Society for Neuroscience 27, 542-552.

Chiu, C.Q., Martenson, J.S., Yamazaki, M., Natsume, R., Sakimura, K., Tomita, S., Tavalin, S.J., and Higley, M.J. (2018). Input-Specific NMDAR-Dependent Potentiation of Dendritic GABAergic Inhibition. Neuron 97, 368-377 e363.

Connelly, W.M., Fyson, S.J., Errington, A.C., McCafferty, C.P., Cope, D.W., Di Giovanni, G., and Crunelli, V. (2013). GABAB Receptors Regulate Extrasynaptic GABAA Receptors. The Journal of neuroscience : the official journal of the Society for Neuroscience 33, 3780-3785.

Dong, Y.N., Wu, H.Y., Hsu, F.C., Coulter, D.A., and Lynch, D.R. (2006). Developmental and cell-selective variations in $\mathrm{N}$-methyl-D-aspartate receptor degradation by calpain. Journal of neurochemistry 99, 206-217.

Farrant, M., and Nusser, Z. (2005). Variations on an inhibitory theme: phasic and tonic activation of GABA(A) receptors. Nat Rev Neurosci 6, 215-229.

Gaiarsa, J.L. (2004). Plasticity of GABAergic synapses in the neonatal rat hippocampus. Journal of cellular and molecular medicine 8, 31-37.

Gambrill, A.C., and Barria, A. (2011). NMDA receptor subunit composition controls synaptogenesis and synapse stabilization. Proceedings of the National Academy of Sciences of the United States of America 108, 5855-5860.

Glykys, J., Mann, E.O., and Mody, I. (2008). Which GABA(A) receptor subunits are necessary for tonic inhibition in the hippocampus? The Journal of neuroscience : the official journal of the Society for Neuroscience 28, 1421-1426.

Gonda, S., Giesen, J., Sieberath, A., West, F., Buchholz, R., Klatt, O., Ziebarth, T., Rak, A., Kleinhubbert, S., Riedel, C., et al. (2020). GluN2B but Not GluN2A for Basal Dendritic Growth of Cortical Pyramidal Neurons. Front Neuroanat 14, 571351.

Gu, X., and Lu, W. (2018). Genetic deletion of NMDA receptors suppresses GABAergic synaptic transmission in two distinct types of central neurons. Neuroscience letters 668 , 147-153.

Gu, X., Zhou, L., and Lu, W. (2016). An NMDA Receptor-Dependent Mechanism Underlies Inhibitory Synapse Development. Cell reports 14, 471-478. 
Han, W., Li, J., Pelkey, K.A., Pandey, S., Chen, X., Wang, Y.X., Wu, K., Ge, L., Li, T., Castellano, D., et al. (2019). Shisa7 is a GABAA receptor auxiliary subunit controlling benzodiazepine actions. Science 366, 246-250.

Han, W., Shepard, R.D., and Lu, W. (2021). Regulation of GABAARs by Transmembrane Accessory Proteins. Trends Neurosci 44, 152-165.

Hardingham, G.E., and Bading, H. (2010). Synaptic versus extrasynaptic NMDA receptor signalling: implications for neurodegenerative disorders. Nat Rev Neurosci 11, 682-696.

Hardingham, G.E., Fukunaga, Y., and Bading, H. (2002). Extrasynaptic NMDARs oppose synaptic NMDARs by triggering CREB shut-off and cell death pathways. Nature neuroscience 5, 405-414.

Hausrat, T.J., Muhia, M., Gerrow, K., Thomas, P., Hirdes, W., Tsukita, S., Heisler, F.F., Herich, L., Dubroqua, S., Breiden, P., et al. (2015). Radixin regulates synaptic GABAA receptor density and is essential for reversal learning and short-term memory. Nature communications 6, 6872 .

Henneberger, C., Juttner, R., Schmidt, S.A., Walter, J., Meier, J.C., Rothe, T., and Grantyn, R. (2005). GluR- and TrkB-mediated maturation of GABA receptor function during the period of eye opening. Eur J Neurosci 21, 431-440.

Hines, R.M., Davies, P.A., Moss, S.J., and Maguire, J. (2012). Functional regulation of GABAA receptors in nervous system pathologies. Curr Opin Neurobiol 22, 552-558.

Holter, N.I., Zylla, M.M., Zuber, N., Bruehl, C., and Draguhn, A. (2010). Tonic GABAergic control of mouse dentate granule cells during postnatal development. Eur J Neurosci 32, 1300-1309.

Horn, M.E., and Nicoll, R.A. (2018). Somatostatin and parvalbumin inhibitory synapses onto hippocampal pyramidal neurons are regulated by distinct mechanisms. Proceedings of the National Academy of Sciences of the United States of America 115, 589-594.

Houser, C.R., and Esclapez, M. (2003). Downregulation of the alpha5 subunit of the $\operatorname{GABA}(A)$ receptor in the pilocarpine model of temporal lobe epilepsy. Hippocampus 13, 633-645.

Jacob, T.C., Moss, S.J., and Jurd, R. (2008). GABA(A) receptor trafficking and its role in the dynamic modulation of neuronal inhibition. Nat Rev Neurosci 9, 331-343.

Jaenisch, N., Liebmann, L., Guenther, M., Hubner, C.A., Frahm, C., and Witte, O.W. (2016). Reduced tonic inhibition after stroke promotes motor performance and epileptic seizures. Sci Rep 6, 26173.

Joshi, S., and Kapur, J. (2009). Slow intracellular accumulation of GABA(A) receptor delta subunit is modulated by brain-derived neurotrophic factor. Neuroscience $164,507-$ 519.

Lee, V., and Maguire, J. (2014). The impact of tonic GABAA receptor-mediated inhibition on neuronal excitability varies across brain region and cell type. Front Neural Circuits 8 , 3.

Li, J., Han, W., Pelkey, K.A., Duan, J., Mao, X., Wang, Y.X., Craig, M.T., Dong, L., Petralia, R.S., McBain, C.J., et al. (2017). Molecular Dissection of Neuroligin 2 and Slitrk3 Reveals an Essential Framework for GABAergic Synapse Development. Neuron 96, 808-826 e808.

Liu, Y., Wong, T.P., Aarts, M., Rooyakkers, A., Liu, L., Lai, T.W., Wu, D.C., Lu, J., Tymianski, M., Craig, A.M., et al. (2007). NMDA receptor subunits have differential roles in mediating excitotoxic neuronal death both in vitro and in vivo. The Journal of neuroscience : the official journal of the Society for Neuroscience 27, 2846-2857. 
Loebrich, S., Bahring, R., Katsuno, T., Tsukita, S., and Kneussel, M. (2006). Activated radixin is essential for GABAA receptor alpha5 subunit anchoring at the actin cytoskeleton. EMBO J 25, 987-999.

Luscher, B., Fuchs, T., and Kilpatrick, C.L. (2011). GABAA receptor trafficking-mediated plasticity of inhibitory synapses. Neuron 70, 385-409.

Marsden, K.C., Beattie, J.B., Friedenthal, J., and Carroll, R.C. (2007). NMDA receptor activation potentiates inhibitory transmission through GABA receptor-associated proteindependent exocytosis of $\operatorname{GABA}(\mathrm{A})$ receptors. The Journal of neuroscience : the official journal of the Society for Neuroscience 27, 14326-14337.

Mathern, G.W., Pretorius, J.K., Leite, J.P., Kornblum, H.I., Mendoza, D., Lozada, A., and Bertram, E.H., 3rd (1998). Hippocampal AMPA and NMDA mRNA levels and subunit immunoreactivity in human temporal lobe epilepsy patients and a rodent model of chronic mesial limbic epilepsy. Epilepsy research 32, 154-171.

McBain, C.J., and Mayer, M.L. (1994). N-methyl-D-aspartic acid receptor structure and function. Physiol Rev 74, 723-760.

McKay, S., Ryan, T.J., McQueen, J., Indersmitten, T., Marwick, K.F.M., Hasel, P., Kopanitsa, M.V., Baxter, P.S., Martel, M.A., Kind, P.C., et al. (2018). The Developmental Shift of NMDA Receptor Composition Proceeds Independently of GluN2 SubunitSpecific GluN2 C-Terminal Sequences. Cell reports 25, 841-851 e844.

Monyer, H., Burnashev, N., Laurie, D.J., Sakmann, B., and Seeburg, P.H. (1994). Developmental and regional expression in the rat brain and functional properties of four NMDA receptors. Neuron 12, 529-540.

Monyer, H., Sprengel, R., Schoepfer, R., Herb, A., Higuchi, M., Lomeli, H., Burnashev, N., Sakmann, B., and Seeburg, P.H. (1992). Heteromeric NMDA receptors: molecular and functional distinction of subtypes. Science 256, 1217-1221.

Muller, L., Tokay, T., Porath, K., Kohling, R., and Kirschstein, T. (2013). Enhanced NMDA receptor-dependent LTP in the epileptic CA1 area via upregulation of NR2B. Neurobiol Dis 54, 183-193.

Naylor, D.E., Liu, H., Niquet, J., and Wasterlain, C.G. (2013). Rapid surface accumulation of NMDA receptors increases glutamatergic excitation during status epilepticus. Neurobiol Dis 54, 225-238.

Naylor, D.E., Liu, H., and Wasterlain, C.G. (2005). Trafficking of GABA(A) receptors, loss of inhibition, and a mechanism for pharmacoresistance in status epilepticus. The Journal of neuroscience : the official journal of the Society for Neuroscience 25, 77247733.

Pan, G., Chen, Z., Zheng, H., Zhang, Y., Xu, H., Bu, G., Zheng, H., and Li, Y. (2018). Compensatory Mechanisms Modulate the Neuronal Excitability in a Kainic Acid-Induced Epilepsy Mouse Model. Front Neural Circuits 12, 48.

Peng, Y.R., Zeng, S.Y., Song, H.L., Li, M.Y., Yamada, M.K., and Yu, X. (2010). Postsynaptic spiking homeostatically induces cell-autonomous regulation of inhibitory inputs via retrograde signaling. The Journal of neuroscience : the official journal of the Society for Neuroscience 30, 16220-16231.

Petrini, E.M., Ravasenga, T., Hausrat, T.J., Iurilli, G., Olcese, U., Racine, V., Sibarita, J.B., Jacob, T.C., Moss, S.J., Benfenati, F., et al. (2014). Synaptic recruitment of gephyrin regulates surface GABAA receptor dynamics for the expression of inhibitory LTP. Nature communications 5, 3921.

Racine, R.J. (1972). Modification of seizure activity by electrical stimulation. II. Motor seizure. Electroencephalogr Clin Neurophysiol 32, 281-294.

Rajgor, D., Purkey, A.M., Sanderson, J.L., Welle, T.M., Garcia, J.D., Dell'Acqua, M.L., and Smith, K.R. (2020). Local miRNA-Dependent Translational Control of GABAAR Synthesis during Inhibitory Long-Term Potentiation. Cell reports 31, 107785. 
Roberts, D.S., Hu, Y., Lund, I.V., Brooks-Kayal, A.R., and Russek, S.J. (2006). Brainderived neurotrophic factor (BDNF)-induced synthesis of early growth response factor 3 (Egr3) controls the levels of type A GABA receptor alpha 4 subunits in hippocampal neurons. The Journal of biological chemistry 281, 29431-29435.

Saliba, R.S., Kretschmannova, K., and Moss, S.J. (2012). Activity-dependent phosphorylation of GABAA receptors regulates receptor insertion and tonic current. EMBO J 31, 2937-2951.

Sepulveda, F.J., Bustos, F.J., Inostroza, E., Zuniga, F.A., Neve, R.L., Montecino, M., and van Zundert, B. (2010). Differential roles of NMDA Receptor Subtypes NR2A and NR2B in dendritic branch development and requirement of RasGRF1. J Neurophysiol 103, 1758-1770.

Sheng, M., Cummings, J., Roldan, L.A., Jan, Y.N., and Jan, L.Y. (1994). Changing subunit composition of heteromeric NMDA receptors during development of rat cortex. Nature 368, 144-147.

Shipton, O.A., and Paulsen, O. (2014). GluN2A and GluN2B subunit-containing NMDA receptors in hippocampal plasticity. Philosophical transactions of the Royal Society of London Series B, Biological sciences 369, 20130163.

Sun, Y., Xu, Y., Cheng, X., Chen, X., Xie, Y., Zhang, L., Wang, L., Hu, J., and Gao, Z. (2018). The differences between GluN2A and GluN2B signaling in the brain. Journal of neuroscience research 96, 1430-1443.

Terasaki, Y., Sasaki, T., Yagita, Y., Okazaki, S., Sugiyama, Y., Oyama, N., OmuraMatsuoka, E., Sakoda, S., and Kitagawa, K. (2010). Activation of NR2A receptors induces ischemic tolerance through CREB signaling. J Cereb Blood Flow Metab 30, 1441-1449.

Turrigiano, G. (2012). Homeostatic synaptic plasticity: local and global mechanisms for stabilizing neuronal function. Cold Spring Harbor perspectives in biology 4, a005736.

Vieira, M., Yong, X.L.H., Roche, K.W., and Anggono, V. (2020). Regulation of NMDA glutamate receptor functions by the GluN2 subunits. Journal of neurochemistry 154, 121-143.

Vincent, P., and Mulle, C. (2009). Kainate receptors in epilepsy and excitotoxicity. Neuroscience 158, 309-323.

Vithlani, M., Terunuma, M., and Moss, S.J. (2011). The dynamic modulation of GABA(A) receptor trafficking and its role in regulating the plasticity of inhibitory synapses. Physiol Rev 91, 1009-1022.

Waxman, E.A., and Lynch, D.R. (2005). N-methyl-D-aspartate receptor subtypes: multiple roles in excitotoxicity and neurological disease. The Neuroscientist : a review journal bringing neurobiology, neurology and psychiatry 11, 37-49.

Wu, K., Han, W., Tian, Q., Li, Y., and Lu, W. (2021). Activity- and sleep-dependent regulation of tonic inhibition by Shisa7. Cell reports 34, 108899.

Wu, Q.J., and Tymianski, M. (2018). Targeting NMDA receptors in stroke: new hope in neuroprotection. Molecular brain 11, 15.

Zhang, X.M., and Luo, J.H. (2013). GluN2A versus GluN2B: twins, but quite different. Neuroscience bulletin 29, 761-772.

Zou, G., Chen, Q., Chen, K., Zuo, X., Ge, Y., Hou, Y., Pan, T., Pan, H., Liu, D., Zhang, L., et al. (2019). Human Hyperekplexic Mutations in Glycine Receptors Disinhibit the Brainstem by Hijacking GABAA Receptors. iScience 19, 634-646. 
Figure 1. Overexpression of GluN2B inhibits tonic inhibition

(A) Overexpression experiment design. Neurons were transfected at 11 days in vitro (DIV11) for $72 \mathrm{~h}$ and then recorded for tonic inhibitory currents at DIV14.

(B) Representative traces and summary graphs showing that GluN2B, but not GluN2A overexpression decreased tonic currents in cultured hippocampal neurons. ( $n=11-13$ for each group, one-way ANOVA test with Dunnett's multiple comparisons test)

(C) Immunostaining and summary graphs showing that GluN2B but not GluN2A overexpression decreased surface $\alpha 5$ expression in cultured hippocampal neurons. ( $\mathrm{n}=$ 28-31 for each group, one-way ANOVA test with Dunnett's multiple comparisons test). (did not show where the amplified region comes from in the images)

(D) Knockout (KO) experiment design. Neurons were transfected at DIV3-4 and then recorded for tonic currents at DIV16-17.

(E) Representative traces and summary graphs showing that GluN2A KO decreased tonic currents, whereas GluN2B KO increased tonic currents. The changes in tonic currents induced by either GluN2A or GluN2B KO were restored back to the control level by co-expression of corresponding sgRNA-resistant constructs, respectively. $(n=8-10$ for each group, one-way ANOVA test Tukey's multiple comparisons test)

${ }^{*} p<0.05$ and ${ }^{* *} p<0.01$. All data are presented as mean \pm SEM. 
Figure 2. Pharmacological suppression of GluN2A- and GluN2B-containing receptors regulate tonic inhibition and $\alpha 5-G A B A_{A} R$ internalization

(A) Experimental design. Hippocampal neurons at DIV 14 were treated with NVP (GluN2A-preferring antagonist NVP-AAM077, 100 nM), Ifen (GluN2B-preferring antagonist ifenprodil, $5 \mu \mathrm{M}$ ), or APV (broad-spectrum NMDAR antagonist, $100 \mu \mathrm{M}$ ) for $24 \mathrm{~h}$ and then recorded for tonic currents at DIV15.

(B) Representative traces and summary graphs showing that 24-h Ifen treatment increased tonic currents, whereas 24-h NVP treatment decreased tonic currents in cultured hippocampal neurons. ( $n=10-11$ for each group, one-way ANOVA with Dunnett's multiple comparisons test)

(C) Immunostaining and summary graphs showing 24-h Ifen treatment increased surface $\alpha 5$ expression, whereas 24-h NVP treatment decreased surface $\alpha 5$ expression in cultured hippocampal neurons. ( $n=33-43$ for each group, Kruskal-Wallis test with Dunnett's multiple comparisons test)

(D) Endocytosis assay of $\alpha 5-G A B A_{A} R s$ in hippocampal cultures. Surface $\alpha 5-G A B A_{A} R s$ $(\mathrm{S} \alpha 5)$ were labeled in green, and internalized $\alpha 5-\mathrm{GABA}_{A} \mathrm{Rs}(\mathrm{l} \alpha 5)$ were in red. Bar graphs in the right showing that 24-h NVP treatment increased $\alpha 5$ internalization, whereas 24-h Ifen treatment decreased $\alpha 5$ internalization. ( $n=15-16$ for each group, one-way ANOVA with Dunnett's multiple comparisons test).

${ }^{*} p<0.05,{ }^{* *} p<0.01$ and ${ }^{* * *} p<0.0001$. All data are presented as mean \pm SEM. 


\section{Figure 3. GluN2A-contaning receptors are required for homeostatic potentiation of} tonic inhibition

(A) Experimental design. Hippocampal neurons at DIV 16 were treated with bicuculline $(\mathrm{BIC}, 40 \mu \mathrm{M})$, and at DIV 17 were treated with NVP $(100 \mathrm{nM})$, Ifen $(5 \mu \mathrm{M})$, or APV (100 $\mu \mathrm{M})$ for $24 \mathrm{~h}$ before recording.

(B-C) Representative traces (B) and summary graphs (C) showing that NVP and APV treatment abolished BIC-induced potentiation of tonic currents in cultured hippocampal neurons. ( $n=10$ for each group, one-way ANOVA with Tukey's multiple comparison test).

(D-E) Immunostaining (D) and summary graphs (E) showing that NVP and APV treatment abolished $\mathrm{BIC}$-induced potentiation of surface $\alpha 5$ expression in cultured hippocampal neurons. ( $n=20-26$ for each group, Kruskal-Wallis test with Dunn's multiple comparisons test).

${ }^{*} p<0.05,{ }^{* *} p<0.01$ and ${ }^{* * *} p<0.0001$. All data are presented as mean \pm SEM. 
Figure 4. Pharmacological suppression of GluN2A- and GluN2B-containing receptors regulate tonic inhibition in the KA-induced seizure model

(A-C) Representative Western blots and summary graphs from cell-surface biotinylation assays showing that surface and total GluN2A (A), GluN2B (B) and $\alpha 5-G A B A_{A} R(C)$ expression in the KA-induced seizure model. ( $n=3$ independent experiments, one-way ANOVA with Dunnett's multiple comparisons test)

(D-E) Representative traces (D) and summary graphs (E) showing that tonic currents in hippocampal CA3 neurons were decreased $1 \mathrm{~h}$ after KA injection, whereas increased 24 $\mathrm{h}$ after KA injection. Ifen or NVP treatment $1 \mathrm{~h}$ prior to KA injection respectively restored the decreased or increased tonic currents at corresponding time point after KA injection. ( $n=10$ for each group, one-way ANOVA with Dunnett's multiple comparisons test).

${ }^{*} p<0.05$ and ${ }^{* *} p<0.01$. All data are presented as mean \pm SEM. 
A

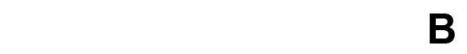

C

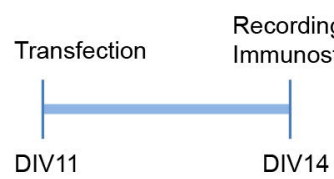

Ctrl
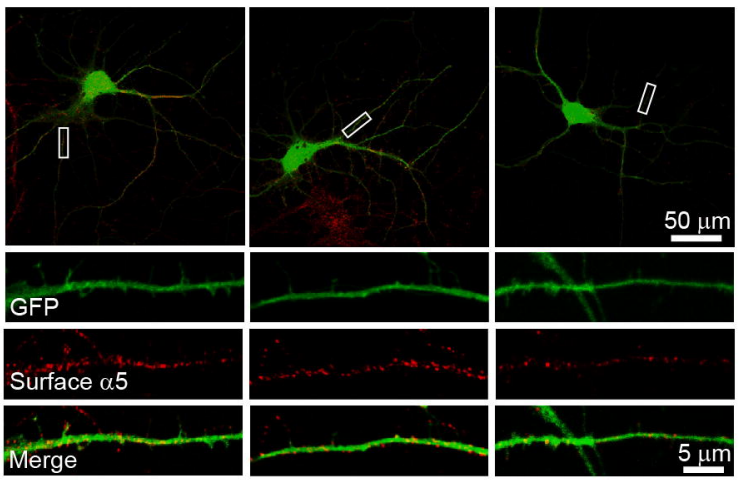

$\frac{\sqrt{10 \mathrm{~s}}}{10 \mathrm{pA}}$
Ctrl
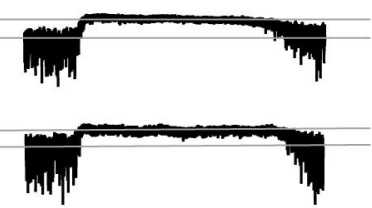

4
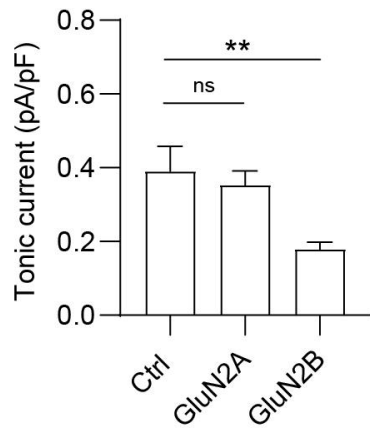

D

Transfection<smiles>C1=CC2CCCCC2C1</smiles>

DIV3-4
Recording

DIV16-17

E

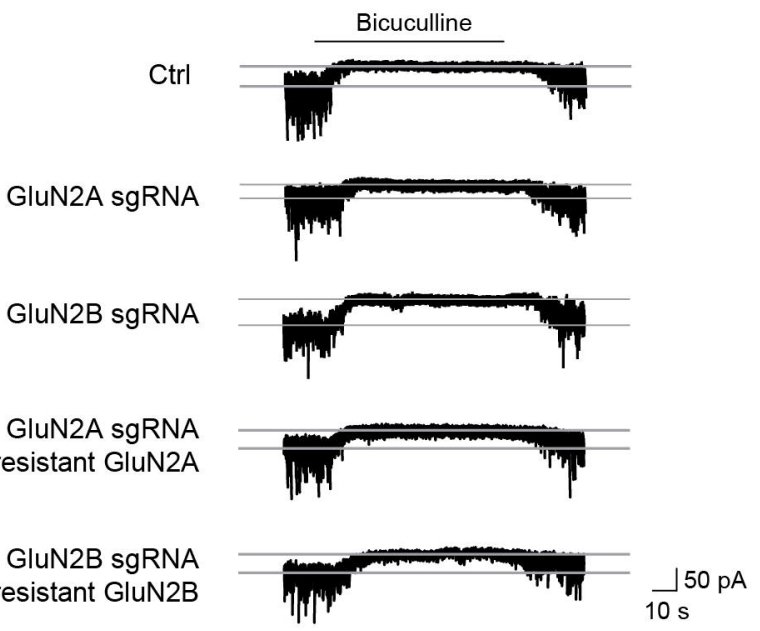

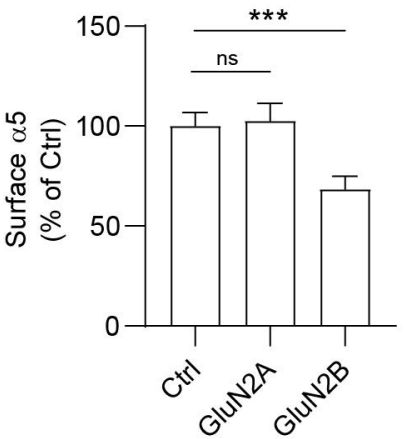

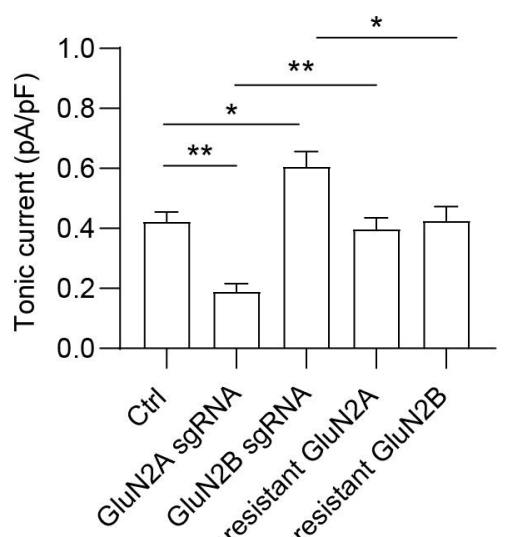




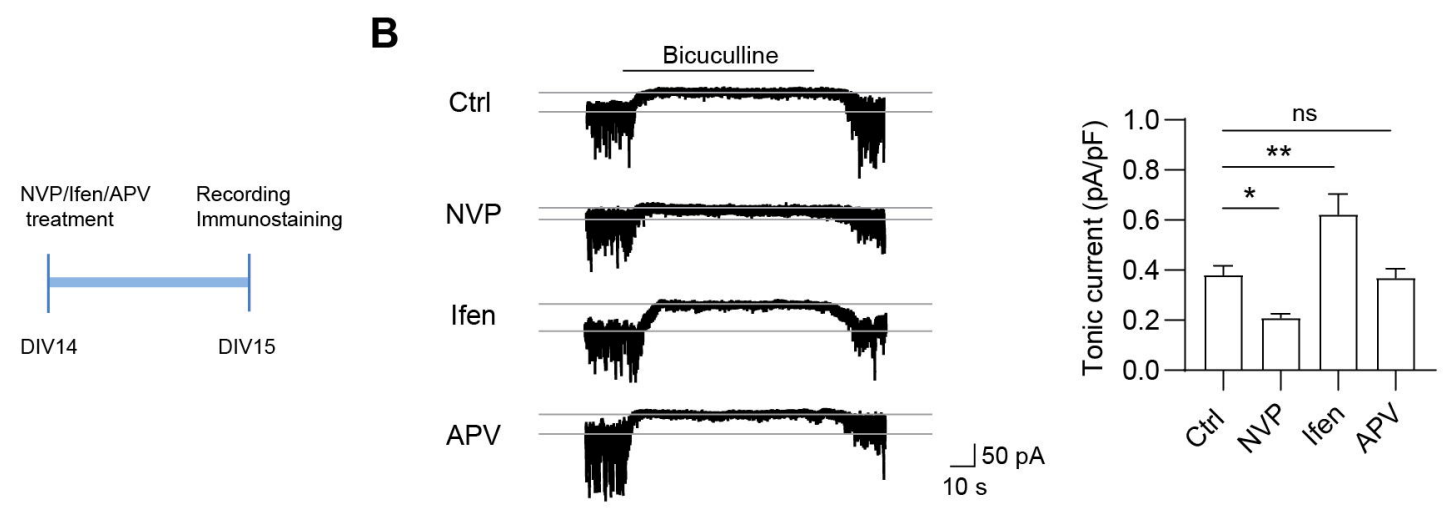

C
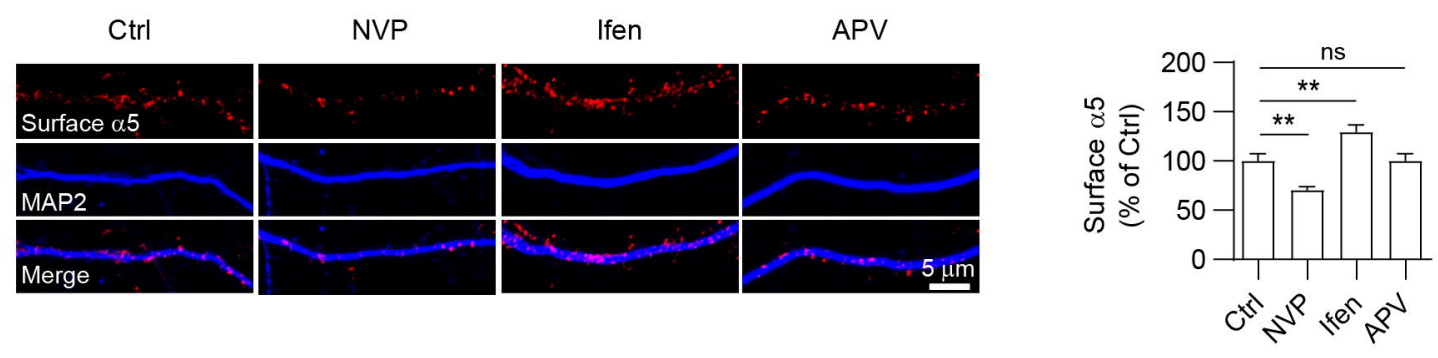

D
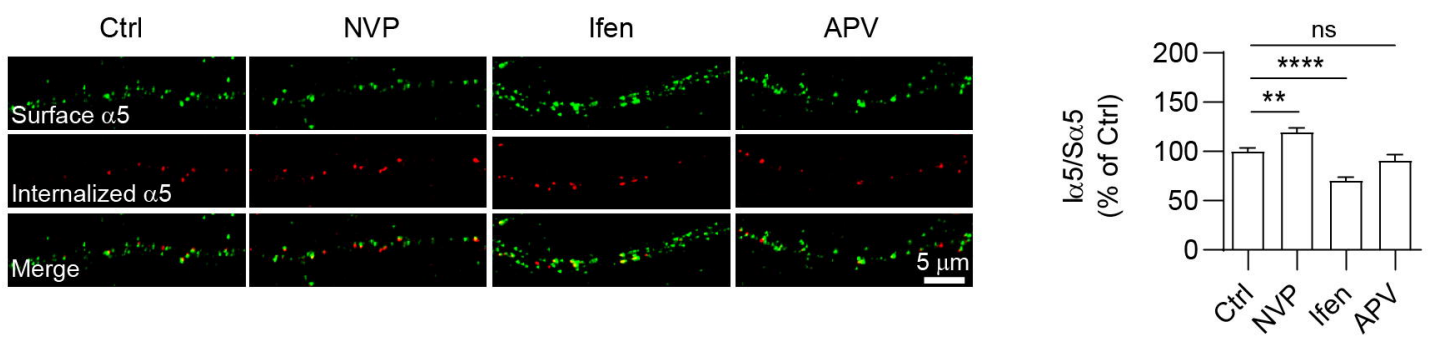
A

NVP/Ifen/APV Recording

BIC treatment treatment Immunostaining

B
DIV16
DIV17
DIV18

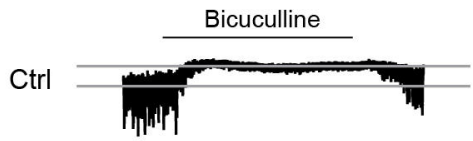

BIC

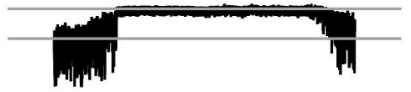

$\mathrm{BIC}+\mathrm{NVP}$

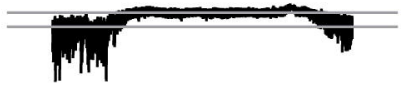

BIC+Ifen

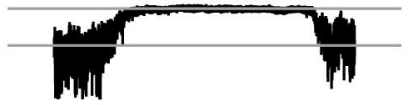

$B I C+A P V$

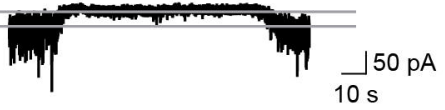

Surface $\alpha 5$

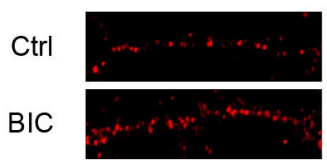

$B I C+N V P$

$B \mid C+I f e n$
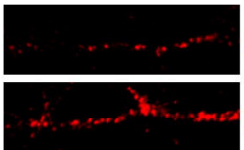

$\mathrm{BIC}+\mathrm{APV}$

C

$\mathbf{E}$

MAP2
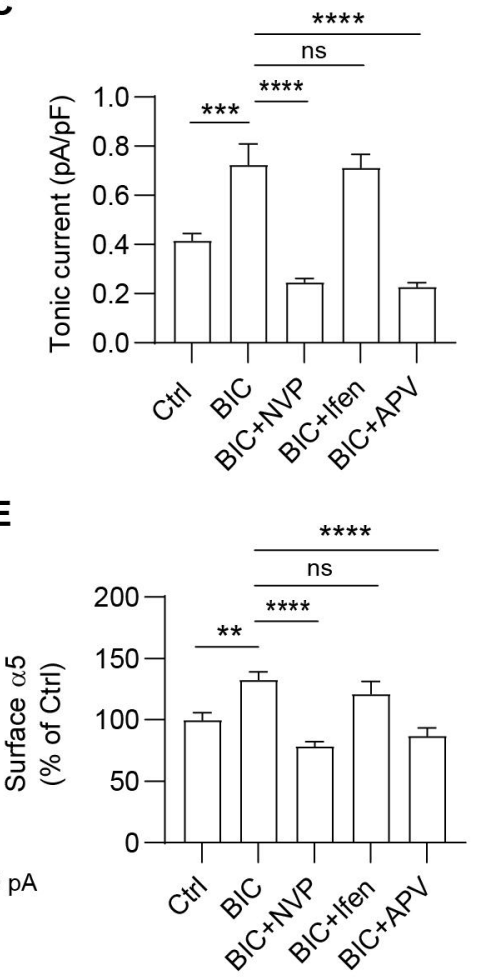

Merge
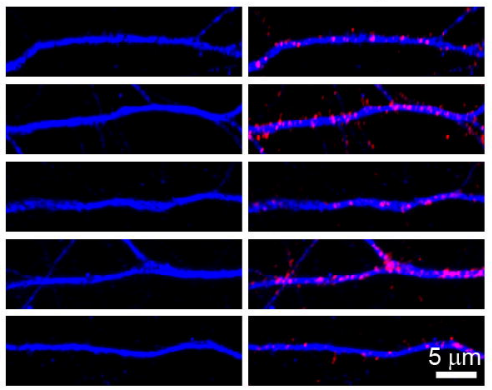
